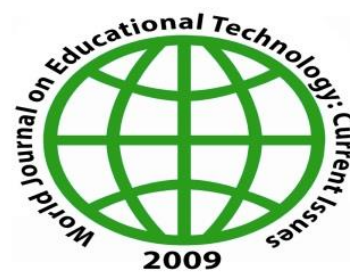

Volume 13, Issue 1, (2021) 106-114

www.wj-et.eu

\title{
The mediation effects of smartphone addiction on relationship between aggression and nomophobia
}

Cahit Nuri, ${ }^{1}$, Department of Special Education, Faculty of Education, Cyprus International University, 99138 Nicosia (via Mersin 10 Turkey), North Cyprus, Cyprus; https://orcid.org/0000-0003-0805-1972

Cemaliye Direktör, Departmant of Psychology, Faculty of Art and Science, European University of Lefke, 99728 Lefke, (via Mersin 10 Turkey), North Cyprus, Cyprus; https://orcid.org/0000-0002-6055-2224

Ahmet Arnavut, Distance Learning Center, University of Kyrenia, Karakum, Girne, Kyrenia, Cyprus; https://orcid.org/0000-0002-2555-8209

\section{Suggested Citation:}

Nuri, C. , Direktör, C. \& Arnavut, A (2021). The mediation effects of smartphone addiction on relationship between aggression and nomophobia. World Journal on Educational Technology: Current Issues. 13(1), 106-114. https://doi.org/10.18844/wjet.v13i1.5403

Received from August 31, 2020; revised from November 20, 2020; accepted from January 20, 2021. Selection and peer review under responsibility of Prof. Dr. Servet Bayram, Yeditepe University, Turkey. (C)2021 Birlesik Dunya Yenilik Arastirma ve Yayincilik Merkezi. All rights reserved.

\begin{abstract}
The aim of this study is to research the mediational role of smartphone addiction on relationship between nomophobia and aggression level of university students. The data collected through the convenience samples over the Internet has reached a wider audience. The study group consisted of 307 university students. Smartphone Addiction Scale Short Form, Buss Perry Aggression Scale and Nomophobia Scale were used during the research process. In addition, Relational survey method used, and mediation model of Baron and Kenny's was used to analyze the mediation effect of smartphone. Smartphone usage is related to nomophobia and anger. Partial mediation effect of smartphone addiction was proved among nomophobia and anger. On the relation between aggression and nomophobia, the smartphone indirect effect value is \%6.
\end{abstract}

Keywords: Aggression, Mediational Role, Nomophobia, Smartphone Addiction

\footnotetext{
*ADDRESS FOR CORRESPONDENCE: Cahit Nuri, Department of Special Education, Faculty of Education, Cyprus International University, 99138 Nicosia (via Mersin 10 Turkey), North Cyprus, Cyprus; Email address: cnuri@ciu.edu.tr ;Tel.: +90 05488880947
} 
Nuri, C. , Direktör, C. \& Arnavut, A (2021). The mediation effects of smartphone addiction on relationship between aggression and nomophobia. World Journal on Educational Technology: Current Issues. 13(1), 106-114. https://doi.org/10.18844/wjet.v13i1.5403

\section{Introduction}

Rapidly developing technology has increased the importance of smartphone usage (Bozkurt, 2013). Smartphone is defined as the integration of computer systems with the telephone system. The fact that smart phones have a reachable and accessible place for the individual and especially their facilitating characteristics for social media applications, has affected the lives of individuals and society in general (Sanal \& Ozer, 2017). In that matter, the prevalence of social networking sites plays a vital role in the development of smart phones. Therefore, it is significant to examine the psychological and sociological dimensions of smartphone use (Balick, 2013). Psychiatric diagnostic criteria have also changed due to the prevalence of use and the category "substance abuse and addiction" in DSM-5 has been replaced by "substance use and addiction disorders" category that included behavioral addictions. As in substance addiction, behavioral addictions also include recurrent behaviors, deterioration of functionality, withdrawal in the real world, tolerance development and withdrawal symptoms, all of which are among the criteria for behavioral addiction (American Psychiatric Association, 2013). There are many studies about the internet usage and related problems. The behavioral dependencies that emerged as internet addiction have led to the development of the concept of smartphone addiction with the prevalence of smartphone usage. Smartphone addiction also includes mood changes such as substance abuse, tolerance, withdrawal, conflict, and relapse. It is reported that in the USA, $64 \%$ of the population is a smart phone user and $46 \%$ of them are problematic users (Pew Research Center, 2015). In the conducted studies, it was observed that smartphone dependence was associated with variables such as loneliness, narcissistic features, low self-esteem (Darcin, Kose, Noyan, Nurmedov, Yilmaz \& Dilbaz, 2016). In addition to the fact that smartphones have an influential place in the life of the individual as a means of social interaction, students spend more time on social networking sites by using their smartphones which reduce their success level (Kirschner \& Karpinski, 2010). In addition, it is reported that individuals are more likely to experience negative feelings (Hew, 2011).

Another concept associated with the smartphone, Nomophobia, represents a state of withdrawal from an environment which creates addiction and pleasure. Due to the fact that being deprived of smartphone is a concern for individuals, it is suggested that nomophobia, as a phobia type, should be added to the Mental Disorders Handbook (DSM) (Bragazzi \& Puente, 2014).

Nomophobia is a notion close to the problems of addiction, but it is considered within the scope of phobias. Nomophobia fears are associated with the negative mental and physical conditions created by these fears. The term nomophobia was first introduced in 2008 by the Postal Service in England. The study conducted by Bahi and Delliis (2015) concluded that $53 \%$ of participants felt anxious when they lost their smartphones, when their battery went flat or when they are out of the coverage area; $58 \%$ of males and $48 \%$ of females reported that they experienced this concern and $49 \%$ of participants stated that they felt under stress when their smartphone was turned off. A study by Secur Envoy (2012) showed that $70 \%$ of females and $61 \%$ of males felt stressed when they could not reach their smartphone and the highest nomophobia ratio was observed in 18-24 age group with 77 percent. A study conducted by Yıldırım, Sumuer, Adnan and Yıldırım (2016) found that $42.6 \%$ of university students in Turkey display nomophobiac behaviors. In the same study, it was reported that the nomophobia level of female participants was higher than male students.

It is revealed that as the anxiety level of the individual increases, he / she can experience the problems of focusing his / her daily activities and may experience sleep irregularities as he / she keeps his / her phone on and checks it frequently during the night (Rosen, Carrier, Miller, Rokkum \& Ruiz, 2016). This, in turn, causes university students to lose motivation and face with sleep disorders in their learning process and decrease in their academic success (Erdem, Kalkın, Turen \& Deniz, 2016). When the studies on nomophobia were examined, relation between nomophobia and loneliness (Traveler, Hamutoglu, Sezen-Gultekin \& Ayas, 2018), decrease in academic achievement (Erdem et al., 2016), excessive internet use (Gezgin \& Cakır, 2016; Gezgin, Cakır \& Yıldırım, 2018), a decrease in self-esteem (Ozdemir, Cakir \& Hussain, 2018), low level of well-being (Ozdemir, Cakir \& Hussain, 2018) has been identified. 
According to social learning theory, aggression is a behavior acquired later by modelling. It has been demonstrated by observational and experimental studies that violent publications are effective on persistent aggressive behaviors in the short and long term (Gumus, Sipkın, Tuna \& Keskin, 2015). It has been reported that the internet has a structure in which several elements of violence have been unrestricted and uncontrolled and that especially children and young people become the target of these elements (Sahin, 2014). Lim et al. (2015) have found that internet addiction and aggression mutually affect each other (Lim, et al. 2015). Similarly, Boumosleh and Jaalouk (2017) reported a positive relationship between type $A$ personality with aggressive features and smartphone addiction. With the development of technology, various psychological problems have emerged. Among these, new generation problems such as internet addiction, smartphone addiction and nomophobia have been included in the field of psychology. Although various studies try to reveal the relationship between aggression and behavioral addictions, it has been observed that studies on the mediating role are quite limited. It is thought that the studies to be conducted in this direction will contribute to the field. The objective of this study is to examine the relation between smart phone addiction and aggression and nomophobia level of young adults studying at university.

\section{Method}

In this study relational survey method was used, and mediation effect of smartphone addiction was analyzed through using mediation analysis method by Baron and Kenny. In order to apply this analysis method, three criteria must be accepted. There is a significant relationship between;

1. Independent variable and mediational variable (a way)

2. Mediational variable and dependent variable (b way)

3. Independent variable and dependent variable (c way)

\section{Participants}

The data was collected from the individuals who could be accessed by using the online data collection technique. Researchers distributed online measurement tools. The distribution was made via the communication through social media. The data was collected via the convenience sampling model. The researchers shared the link of the study form in the whatsapp groups of the universities. Thus, it has been reached to a wider audience over the Internet. The study group consisted of 307 graduate students (female $=139$, male $=168$ ).

\section{Measures}

\section{Smart Phone Addiction Scale Short Form}

The scale generated by Kwon et al. (2013) consists of 10 items. Adaptation to Turkish was carried out by Noyan, Darcin, Nurmedov, Yılmaz and Dilbaz (2015). Within the study conducted by the researchers, it was stated that the scale had a single factor structure which explained $46.3 \%$ of the total variance. The Cronbach Alpha value of the scale was reported as .87 and the test-retest reliability value was reported .98 .

\section{Buss Perry Aggression Scale}

The scale consists of 34 items with five-point Likert-type questions (Buss and Perry, 1992). The best score achieved is 170 and the lowest score is 34 . Aggression Scale has five subscales, particularly anger, verbal aggression, physical aggression, hostility and indirect aggression. The Turkish version of the scale, that was developed in order to determine the extent of aggression, was adapted by DemirtasMadran (2012). The Cronbach Alpha value of the scale was reported as .85. 
Nuri, C. , Direktör, C. \& Arnavut, A (2021). The mediation effects of smartphone addiction on relationship between aggression and nomophobia. World Journal on Educational Technology: Current Issues. 13(1), 106-114. https://doi.org/10.18844/wjet.v13i1.5403

\section{Nomophobia Scale}

In order to measure the nomophobia scores of individuals, Nomophobia Scale, which was developed by Yıldırım and Correira (2015) and adapted to Turkish by Yıldırım (2015) was used. The scale consists of 20 items with 7 likert-type questions. The scale has four subscales which are called "not being able to reach to information", "losing connectedness", not being able to communicate" and "giving up convenience". The Cronbach Alpha value of the scale was reported as .92. Total scores were used in this study.

\section{Analysis of Data}

Mediation analysis method is used in this study. The aim of the study is to predict the causality between dependent and independent variable using mediation analysis.

\section{Results}

Table 1. Relationships between smartphone, nomophobia and anger subscales

\begin{tabular}{lll}
\hline & 1 & 2 \\
\hline Nomophobia & - & \\
Smartphone & $.303^{* * *}$ & - \\
Physical aggression & $.114^{*}$ & $.288^{* * *}$ \\
Verbal aggression & .070 & $.285^{* * *}$ \\
Hostility & .067 & $.449^{* * *}$ \\
Anger & $.123^{*}$ & $.430^{* * *}$ \\
\hline
\end{tabular}

${ }^{*} \mathrm{p}<.05 ;{ }^{* *} \mathrm{p}<.01 ;{ }^{* * *} \mathrm{p}<.001$

The relation between the variables within the study are illustrated on Table 1. It has been noted that smartphone addiction and anger are correlative to the nomophobia at a low level. In addition, physical aggression, verbal aggression, verbal hostility and anger are corelated to the smartphone at a low level.

Table 2. The results of the regression analysis

\begin{tabular}{lllllll}
\hline Dependent & Independent & $\mathrm{B}$ & Standart Error & $\beta$ & $\mathrm{t}$ & $\mathrm{p}$ \\
\hline Nomophobia & Smartphone & .402 & .072 & .304 & 5.547 & $.000^{* * *}$ \\
$\mathrm{R}=.303, \mathrm{R}^{2}=.092, \mathrm{~F}(1,305)$ & $=31.085, \mathrm{p}<.001$ & & & & & \\
\hline Smartphone addiction & Verbal aggression & .075 & .015 & .285 & 5.184 & $.000^{* * *}$ \\
& Physical aggression & .146 & .028 & .288 & 5.259 & $.000^{* * *}$ \\
& Hostility & .217 & .025 & .449 & 8.781 & $.000^{* * *}$ \\
& Anger & .156 & .019 & .430 & 8.317 & $.000^{* * *}$
\end{tabular}

Verbal aggression; $R=.285, R^{2}=.081, F(1,305)=26.869, p<.001$

Physical aggression; $R=.288, R^{2}=.083, F(1,305)=27.661, p<.001$

Hostility; $R=.449, R^{2}=.202, F(1,305)=77.104, \beta=.449, p<.001$

Anger; $R=.430, R^{2}=.185, F(1,305)=69.170, \beta=.430, p<.001$

\begin{tabular}{lllllll}
\hline Nomophobia & Verbal aggression & .025 & .020 & .070 & 1.223 & .222 \\
& Physical aggression & .077 & .038 & .114 & 2.013 & .045
\end{tabular}


Nuri, C. , Direktör, C. \& Arnavut, A (2021). The mediation effects of smartphone addiction on relationship between aggression and nomophobia. World Journal on Educational Technology: Current Issues. 13(1), 106-114. https://doi.org/10.18844/wjet.v13i1.5403

$\begin{array}{llllll}\text { Hostility } & .043 & .037 & .067 & 1.180 & .239 \\ \text { Anger } & .059 & .027 & .123 & 2.168 & .031^{*}\end{array}$

Verbal aggression; $R=.070, R^{2}=.005, F(1,305)=1.497, p>.05$

Physical aggression; $R=.114, R^{2}=.013, F(1,305)=4.052, p=.05$

Hostility; $R=.067, R^{2}=.005, F(1,305)=1.392, \beta=.067, p>.05$

Anger; $R=.123, R^{2}=.015, F(1,305)=4.698, \beta=.123, p<.01$

${ }^{*} \mathrm{p}<.05 ;{ }^{* *} \mathrm{p}<.01 ;{ }^{* * *} \mathrm{p}<.001$

Mediation effect of understanding of smartphone addiction was evaluated in relations among nomophobia and anger (table 2). Significant effect of nomophobia on understanding of smartphone addiction ('a' way; $F(1,305)=31.085, \beta=.304, p=.000$ ). For the second criteria the effects of smartphone addictions on physical aggression, verbal aggression and hostility were evaluated and significant value were indicated (Respectively $F(1,305)=27.661, \beta=.288, p=.000 ; F(1,305)=26.869, \beta=.285, p=.000$; $F(1,305)=77.104, \beta=.449, p=.000)$. But the third criteria was not realized for each variables, in other words, nomophobia was not a predictor of physical aggression, verbal aggression and hostility (Respectively $F(1,305)=4.052, \beta=.114, p=.05 ; F(1,305)=1.497, \beta=.070, p=.222 ; F(1,305)=1.392, \beta=.067$, $\mathrm{p}=.239$ ).

Evaluation of conditions according to mediator role of smartphone addiction defined that nomophobia predicts smartphone significantly $F(1,305)=31.085, \beta=.304, p=.000)$. For the second criteria the effect of smartphone addiction on anger was evaluated and significant value was indicated $(F(1,305)=69.170$, $\beta=.430, p=.000)$. The third criteria was realized as significant prediction of nomophobia effect on anger $(F(1,305)=4.698, \beta=.123, p=.031)$.

\section{Schem 1.}

In Scheme 1. Mediation role effect a, b, c, $c^{1}$ ways of understanding smartphone addiction among nomophobia and anger.

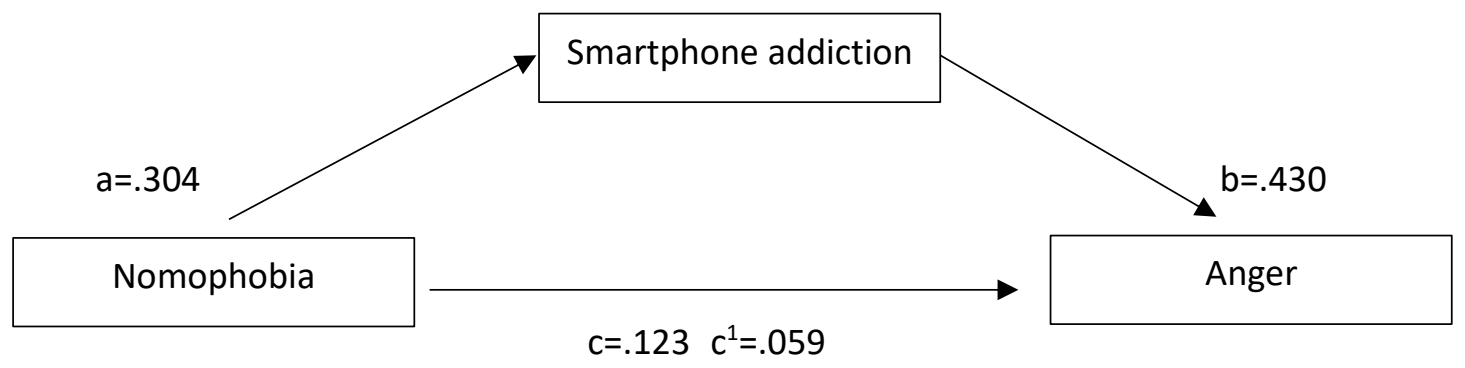

Sobel $Z$ score $=4.5264 p=.000$

As a next step, mediator variable was included into the model to evaluate the mediate effect. At Schema 1 , the significance of the $a, b, c, c 1$ ways is noticeable.

On the evaluation of $c 1$ way, $\beta$ value decreased from .123 to .059 . In order to understand if this reduction is due to the effect of mediator variable, Sobel Test was applied. On the evaluation of the total effect and direct effect, it is indicated that, the difference is $6 \%$ of the indirect effect value. The presence and significance of indirect effect, was analyzed by using Bootsrap credence interval.

Table 3. Mediation effect of smartphone addiction relations on nomophobia and anger 
Nuri, C. , Direktör, C. \& Arnavut, A (2021). The mediation effects of smartphone addiction on relationship between aggression and nomophobia. World Journal on Educational Technology: Current Issues. 13(1), 106-114. https://doi.org/10.18844/wjet.v13i1.5403

\begin{tabular}{llllll}
\hline $\begin{array}{l}\text { Mediation effect of } \\
\text { smartphone addiction }\end{array}$ & $\begin{array}{l}\text { Total } \\
\text { effect }\end{array}$ & Direct effect & $\begin{array}{l}\text { Indirect } \\
\text { effect }\end{array}$ & $\begin{array}{l}\text { BoLLCl- } \\
\text { BoULCl }\end{array}$ & $\begin{array}{l}\text { Mediation } \\
\text { effect type }\end{array}$ \\
\hline Nomophobia-Anger & .123 & .059 & .063 & $.0374-.0935$ & Partial \\
\hline
\end{tabular}

The analysis of the results, indicate that lower and higher limits are subzero. Partial mediation effect of smartphone addiction was proved on nomophobia and anger. When it comes to the evaluation of the total effect and direct effect, it is demonstrated that, the difference is $\% 6$ of indirect effect value. According to this outcome, it could be postulated that understanding of smartphone addiction has a partial mediation effect on nomophobia and anger.

\section{Discussion}

Smartphone addiction plays an intermediary role in the relationship between nomophobia and anger. Problematic internet users usually go through three stages (Polat, 2017). The person has discovered the magical world of the internet and has been influenced by this situation. The second stage is the obsession. At this stage, the person is stuck in this magical world and starts to spend more time. Being connected to the internet, which becomes an addiction, is enough for the person to complete his position in this phase. As long as one is stuck in the magical world, he/she becomes a truly dependent individual. In this case, people make the Internet the center of their lives and, in fact, negatively affect their daily lives with their own hands. The third stage is the frustration / retreat phase. In this case, the person has passed to the last stage and is able to overcome obsession. At this stage, there is a situation of disappointment and retreat from the internet. He has recovered himself when he could not reach the required use and satisfaction. The distinction between internet and traditional socialization is blurred. It is becoming increasingly common for internet users to start their social activities or relationships in the virtual world and move them into the real world, making it difficult to determine whether social activity is virtual or real. In this case, people cannot separate the virtual world from real world and disappear within the virtual reality (Algul \& Ucer, 2013; Cubukcu \& Bayzan, 2013).

The second finding is that the addiction of smartphones predicts hostility, physical aggression, verbal aggression, and anger, whereas nomophobia only predicts anger. Augner and Hacker (2012) and Hong, Chiu and Huang (2012) reported that there is a connection between problematic phone use and psychological conditions such as mental depression, introversion and anxiety. In my study, it was found that personality traits had an effect on nomophobia, albeit at a low rate. Augner and Hacker (2012) and Hong, Chiu and Huang (2012) reported that there is a connection between problematic phone use and psychological conditions such as mental depression, introversion and anxiety. Kıng, Valença, Sılva, Sancassıwan, Machado and Nardi (2014) have found that internet addiction and aggression affect each other mutually (Lim, et al. 2015). Similarly, Boumosleh and Jaalouk (2017) reported a positive relationship between type A personality with aggressive features and smartphone addiction.

Nomophobia emerges when people are away from their smartphone and cannot look to find what is needed or just to gain information (Zethy \& Octaviani, 2017). Although Nomophobia is a concept close to addiction / addiction problems, it is considered within the scope of phobias and is associated with unfavorable fears and negative psychological and physical situations created by these fears (Erdem, Kalkın, Turen \& Deniz, 2016). Therefore, nomophobia can affect anger over society in the digital age. Depressed individuals can use their smart phones more in order to avoid negative emotions which may cause individuals to experience more depressive symptoms, irritability and stress (Elhai, Dvorak, Levine \& Hall, 2017). In the literature, there are studies that have identified significant relationships between problematic internet use and loneliness and depression (Morahan-Martin \& Schumacher, 2000; Shaw \& Gant, 2002). As a result, irrational anxiety and fears, lack of interest and support can lead to an increase in the anger level of the person resulting from depression and nomophobia feeding each other. 
Nuri, C. , Direktör, C. \& Arnavut, A (2021). The mediation effects of smartphone addiction on relationship between aggression and nomophobia. World Journal on Educational Technology: Current Issues. 13(1), 106-114. https://doi.org/10.18844/wjet.v13i1.5403

Another finding of the study is that there is a relationship between nomophobia and physical aggression, smart phone and anger, but there is no relationship between verbal aggression and hostility. In the literature, it has been suggested that nomophobia should be considered as specific phobia, but Traveler, Shumuer, Arslan and Yildirim (2017) stated that nomophobian might accompany smartphone addiction. Behavioral dependency is discussed in six sub-scales by Griffiths (2005). The attention-grabbing sub-dimension corresponds to the fact that a particular activity becomes the most important activity in a person's life and affects his emotions, thoughts and behaviors. "Emotional Regulation" sub-dimension includes the continuation of the activity by the individual but his/her desire for overcoming it. "Tolerance" implies the gradual increase of the time spent by the individual to perform this activity. "Deprivation Symptoms" indicates the individual experiencing unwanted emotions and psychological effects when he/she is prevented from doing an activity he/she desires (nervousness, distemper, anxiety etc.). The "Conflict" sub-dimension corresponds to the conflicts that the person lives in or around itself. The "Relapse" sub-dimension includes repeated attempts to discontinue the activity, the failure of the individual to take control of the activity, and his/her reinstatement. Increase of the addiction of individuals to smartphones may cause them to create irrational thoughts about smartphones. When depressed people are unable to reach their smartphones or use their smartphones, their levels of anxiety and fear may rise, they may have fear of missing the actual agenda or have difficulty in dealing with negative emotions.

\section{Conclusion and Recommendation}

When the results of the study were examined, it was observed that there was a minimum level of positive significant relationship between nomophobia and smartphone, physical aggression and anger. In addition, there is a positive low level between the smartphone and physical aggression and verbal aggression; It was determined that there is a moderately significant positive and moderate relationship between hostility and anger.

When the results of the regression analysis for mediational role analysis are examined, it is seen that smartphone and anger are significant predictors of nomophobia; verbal, physical aggression and hostility were not found to be significant predictors of nomophobia. It has also been observed that verbal aggression, physical aggression, hostility and anger are significant predictors of the smartphone separately.

As a result of the mediation role analysis conducted in line with the main purpose of the study, it was found that the smartphone had a mediator role in the relationship between nomophobia and anger; This effect was determined to be $6 \%$.

Working with a larger sample in future studies will provide a richer contribution to the field. Only university students were included in this study, studies with different age groups will provide the opportunity to compare with other age groups. Various studies have shown that impulsivity is important in addictions. It has been suggested to add the level of impulsivity as a variable in future studies.

\section{References}

Algul, A., \& Ucer, N. (2013). Democracy in New Media. Konya: Literatürk Publications.

American Psychiatric Association. (2013). Diagnostic and statistical manual of mental disorders (DSM-5 $\left.{ }^{\circledR}\right)$. American Psychiatric Pub.

Augner, C., \& Hacker, G.W. (2012). Associations between problematic mobile phone use and psychological parameters in young adults. International Journal of Public Health, 57(2), 437-441. https://doi.org/10.1007/s00038- 011-0234-z

Bahı, R.R. \& Deluliss, D. (2015). “Nomophobia”, (Ed.) Yan, Z., Encyclopedia of Mobile Phone Behavior (Volumes 1,2\&3), IGI Global, Hershey, PA. 
Nuri, C. , Direktör, C. \& Arnavut, A (2021). The mediation effects of smartphone addiction on relationship between aggression and nomophobia. World Journal on Educational Technology: Current Issues. 13(1), 106-114. https://doi.org/10.18844/wjet.v13i1.5403

Balick, A. (2013). The Psychodynamics of Social Networking: Connected-up Instaneous Culture and the Self. Psychoanalysis and Popular Culture. London: Karnac Books.

Bozkurt, I. (2013). Psikolojik Yardım Uygulamalarında Yeni Trend: Online Terapiler [New Trend in Psychological Help Applications: Online Therapies]. International Journal of Human Science, 110,130-146.

Bragazzi, N. L., \& Del Puente, G. (2014). A proposal for including nomophobia in the new DSM-V. Psychology Research and Behavior Management, 7, 155.

Buss, A.H., \& Perry, M. (1992). The aggression questionnaire. Journal of Personality and Social Psychology, 63:452-459.

Cubukcu, A., \& Bayzan, Ş. (2013). Digital citizenship perception in Turkey and the ways to improve this perception through conscious, safe and effective use of internet. Middle Eastern \& African Journal of Educational Research, 5, 148-174.

Darcin, A.E., Kose, S., Noyan, C.O., Nurmedov, S., Yılmaz, O. \& Dilbaz, N. (2016). Smartphone addiction and its relationship with social anxiety and loneliness. Behaviour \& Information Technology, 35, 520-525.

Elhai, J. D., Dvorak, R. D., Levine, J. C., \& Hall, B. J. (2017). Problematic smartphone use: A conceptual overview and systematic review of relations with anxiety and depression psychopathology. Journal of Affective Disorders, 207 (February 2016), 251-259. https://doi.org/10.1016/i.jad.2016.08.030.

Erdem, H., Kalkın, G., Turen, U., \& Deniz, M. (2016).The effect of mobile phone deprivation fear (nomophobia) on academic achievement in university students. Suleyman Demirel University Journal of Faculty of Economic and Administrative Sciences, 21(3).

Gezgin, D. M., Hamutoglu, N. B., Sezen-Gultekin, G., \& Ayas, T. (2018). The Relationship between Nomophobia and Loneliness among Turkish Adolescents. International Journal of Research in Education and Science, $4(2), 358-374$.

Gezgin, D.M., \& Cakır, O. (2016). Analysis of nomophobiac behaviors of adolescents regarding various factors. Journal of Human Sciences, 13(2), 2504-2519.

Gezgin, D.M., Sumuer, E., Arslan, O., \& Yıldırım, S. (2017). Nomophobia prevalence among pre-service teachers: A case of Trakya University. Trakya Universitesi Egitim Fakültesi Dergisi, 7(1).

Griffiths, M.D. \& Davies, M.N.O. (2005). Videogame Addiction: Does It Exist? Handbook of Computer Game Studies. J. Goldstein, J. Raessens (Eds), Boston. MIT Pres, p.359-368.

Gumus, A.B., Sıpkın, S., Tuna, A., \& Keskin, G. (2015). The relationship between problematic internet use, violence tendency and some demographic variables in university students. TSK Protective Medicine Bulletin, 14:458-465.

Hew, K. F. (2011). Students' and teachers' use of Facebook. Computer Human Behaviour, 27(2): 662-676.

Hong, F. Y., Chiu, S. I., \& Huang, D. H. (2012).A model of the relationship between psychological characteristics, mobile phone addiction and use of mobile phones by Taiwanese university female students. Computers in Human Behavior, 28(6), 2152-2159.

King, A. L. S., Valenca, A. M., Silva, A. C., Sancassiani, F., Machado, S., \& Nardi, A. E. (2014). “Nomophobia”: impact of cell phone use interfering with symptoms and emotions of individuals with panic disorder compared with a control group. Clinical Practice And Epidemiology In Mental Health: CP \& EMH, 10, 28.

Kirschner, P.A. \& Karpinski, A.C. (2010). Facebook and Academic Performance. Computer Human Behaviour, 26,1237-1245.

Kwon, M., Lee, J.Y., Won, W.Y., Park, J.W., Min, J.A., Hahn, C., Gu, X., Choi, J.H. \& Kim, D.J. (2013). Development and validation of a Smartphone Addiction Scale (SAS). PLoS One, 8:e56936.

Lim, J.A., Gwak, A.R., Park, S.M., Kwon, J.G., Lee, J.Y., Jung, H.Y., et al. (2015). Are adolescents with internet addiction prone to aggressive behavior? The mediating effect of clinical comorbidities on the predictability of aggression in adolescents with internet addiction. Cyberpsychology, Behavior, and Social Networking, $18,260-267$.

Matar Boumosleh, J., \& Jaalouk, D. (2017). Depression, anxiety, and smartphone addiction in university studentsA cross sectional study. PLoS one, 12(8). 
Nuri, C. , Direktör, C. \& Arnavut, A (2021). The mediation effects of smartphone addiction on relationship between aggression and nomophobia. World Journal on Educational Technology: Current Issues. 13(1), 106-114. https://doi.org/10.18844/wjet.v13i1.5403

Morahan-Martin, J., \& Schumacher, P. (2000). Incidence and correlates of pathological internet use among college students. Computers in Human Behavior, 16(1), 13-29. https://doi.org/10.1016/S07475632(99)00049-7.

Noyan, C.O., Darcin, A.E., Nurmedov, S., Yilmaz, O. \& Dilbaz, N. (2015).The validity and reliability study of the Turkish version of the short form of Smart Phone Dependence Scale in Turkish university students. Anadolu Psychiatry Journal,16 (Additional Issue 1):73-81.

Ozdemir, B., Cakir, O., \& Hussain, I. (2018). Prevalence of Nomophobia among University Students: A Comparative Study of Pakistani and Turkish Undergraduate Students. Eurasia Journal of Mathematics, Science and Technology Education, 14(4), 1519-1532.

Pew Research Center, (2015)."The Smartphone Difference.”. http://www.pewinternet.org.

Polat, R. (2017). Dijital Hastalik Olarak Nomofobi. Yeni Medya Elektronik Dergisi, 1(2), 164-172.

Rosen, L., Carrier, L. M., Miller, A., Rokkum, J., \& Ruiz, A. (2016). Sleeping with technology: cognitive, affective, and technology usage predictors of sleep problems among college students. Sleep health, 2(1), 49-56.

Sahin, M. (2014). The internet addiction and aggression among university students. Dusunen Adam: Journal of Psychiatry and Neurological Sciences, 27:43-52.

Sanal, Y., \& Ozer, O. (2017). Smartphone Addiction and the Use of Social Media among University Student. Mediterranean Journal of Humanities mjh. akdeniz. edu. $\operatorname{tr}$ VII/2 (2017), 367-377.

Securenvoy. (2012). "66\% of The Population Suffer from Nomophobia The Fear of Being without Their Phone", https://www.securenvoy.com/blog/2012/02/16/66-ofthe-population-suffer-from-nomophobia- thefear-of-being-without-their-phone, 20.12.2015.

Shaw, L. H. \& Gant, L. M. (2004). In defense of the internet: The relationship between internet communication and depression, loneliness, self-esteem, and perceived social support. CyberPsychology \& Behavior, 5(2), 157-171. https://doi.org/10.1089/109493102753770552.

Yildirim, C., \& Correia, A. P. (2015). Exploring the dimensions of nomophobia: Development and validation of a self-reported questionnaire. Computers in Human Behavior, 49, 130-137. https://doi.org/10.1016/i.chb.2015.02.059

Yildirim, C., Sumuer, E., Adnan, M., \& Yildirim, S. (2016). A growing fear: Prevalence of nomophobia among Turkish college students. Information Development, 32(5), 1322-1331. https://doi.org/10.1177/0266666915599025

Zethy, C. \& Octaviani, U. F. (2017). Nomophobia Around Us!. Journal of Innovative Research in Social Sciences \& Humanities (JIRSCH). 